\title{
Understanding the intrinsic nature of the trends of digital innovation: A main path analysis
}

\author{
Chen-Hao Huang \\ National Taiwan University \\ of Science and Technology \\ chhuang@mail.ntust.edu.tw
}

\author{
Tzu-Chuan Chou \\ National Taiwan University \\ of Science and Technology \\ tcchou@mail.ntust.edu.tw
}

\author{
John S. Liu \\ National Taiwan University \\ of Science and Technology \\ johnliu@mail.ntust.edu.tw
}

\begin{abstract}
Digital innovation plays an increasingly important role in an organizational context. During the past two decades, IS scholars have witnessed a rapid growth of research interest in digital innovation. However, its nature and implications are still vague. More specifically, the intrinsic nature of digital innovation is changing with the development of technology and society. The purpose of this article is to examine digital innovation from various perspectives and thus provide potential research directions for future research. This study adopts main path analysis, a citation-based systematic review method, collecting and analyzing 848 digital innovation-related academic articles. It traces the most significant paths and reveals seven popular research themes, including digital innovation management, recombination approach, entrepreneurship, transformation, institution and management control, and data-driven value capture. This study furthers the understanding of digital innovation in the current IS research and presents research opportunities that are valuable for future work.
\end{abstract}

\section{Introduction}

The concept of digital innovation is growing with the wide adoption of digital technologies. In the early days of this field, digital innovation referred to combining digital technologies with physical components so that products change to innovative ones [1], such as digital imaging [2], digital music [3], digital newspapers [4] and so on. Organizations are under increasing pressure to pursue digital innovation [5]. Over the past decades, IS scholars have extended the scope of digital innovation from a product level to multi-level, discussed the various emerging digital aspects caused by digitalization, and termed this process "digital transformation" $[6,7]$ or "digital disruption" [8,9] to further discuss the phenomenon of digital innovation. Despite digital innovation arousing a great deal of interest among both researchers and practitioners, the role of digital innovation is changing with the development of society and technology. Such rapid changes urgently require a more comprehensive review of digital innovation.

In 2010, Yoo, Henfridsson, and Lyytinen [1] published a research agenda that explained how digitalization enabled a new structure of product architecture with four loosely coupled layers. After this, a conceptualized framework established, the related digital-based innovation has aroused an amount of notice. For example, digital technologies have been understood as technological tools in the service delivery process [10], allowing users to create, storing, and consuming content, thus creating new markets or categories of services, and even business models $[11,12]$. Digital technologies enabled a series of resource recombination to empower information to be restructured in multi-context, and permit actors to create and capture more value in this process [13]. Indeed, digital technologies play a crucial role in an organization to accomplish digital innovation and transformation and benefit enterprises [14]. Despite there being a growing number of organizations that indicate that digital innovation initiatives have been conducted in their organization, the concept of digital innovation may differ in each organization and changing environment. For example, the research indicates Amazon's Kindle as a digital innovation case [15] which, through the digitization of well-established products, blurs industry boundaries and creates new threats and opportunities. On the other hand, some studies recognized that organizations appropriate the innovative digital technologies of other companies into their work environment to represent the other type of digital innovation. However, while practitioners and scholars promote the importance of digital innovation in the organization, its precise meaning and the relationship between each research stream in digital innovation discourse remains clearly defined and divided.In building the prospective theory for further 
studies, we examine two questions:

1.) How is the research on digital innovation literature developing?

2.) What is new in digital innovation?

To answer the questions, we conducted a systematic review by collecting and analyzing 848 digital innovation-related academic papers. This study aims to examine the digital innovation existing literature and therefore provide a research road map for future research.

\section{Methodology}

Main path analysis (MPA) is a way of tracing the key development path of a scientific discipline through citation links. It was first introduced by Hummon and Doreian [16], and now has been widely adopted in a wide variety of disciplines [17, 18, 19]. These essential trajectories hint the most impactful studies and the main knowledge flow paths of a specific field [20]. Based on the main knowledge flow, we can further the understanding of the development of digitalization in the IS filed.

\subsection{Key-route main path analysis}

Compared to the traditional systematic literature survey, MPA allows the study to examine multiple journals from various fields at the same time rather than focus on specific journals. This approach involves of two steps. The first step calculates the traversal counts of each citation link in a citation network [16] and as a results, differentiating the significance of each citation link. Among the various traversal count algorithms, this study adopts the search path link count (SPLC) algorithm based on the suggestion in Liu et al. [21] and Liu et al.[22]. The second step explores the crucial trajectory by connecting the significant citation links into a path according to the value of traversal counts. Liu and Lu [23] purposed key-route MPA, which makes the main path analysis more practical than the traditional approach. In specific, key-route MPA not only searches for multiples paths but also ensures that all the top significant links are included in the final results [23, 24]. This approach empowers the research not ignoring important contributors. Therefore, this research applies key-route MPA to visualize the key knowledge development trajectory of digital innovation. Key-route MPA is always associated with a key-route number which indicates the number of top links to include in the resulting main paths.

Table 1. Search strategy and key words used

\begin{tabular}{|c|c|}
\hline Database & Web of Science \\
\hline $\begin{array}{l}\text { Search } \\
\text { Strategy }\end{array}$ & $\begin{array}{l}\text { TS=(("Digital" or "Digitally") AND } \\
\text { ("Innovation" or "Transformation" or } \\
\text { "Disruption")) }\end{array}$ \\
\hline $\begin{array}{l}\text { Document } \\
\text { Type }\end{array}$ & Article OR Early Access OR Review \\
\hline $\begin{array}{l}\text { Search } \\
\text { Area }\end{array}$ & $\begin{array}{l}\text { management and information science } \\
\& \text { library science }\end{array}$ \\
\hline Time Span & $\begin{array}{l}\text { From January } 1^{\text {st }} 2000 \text { to June } 13^{t h} \\
2020\end{array}$ \\
\hline
\end{tabular}

\subsection{Literature search}

This study collect academic articles and associated citation information from the Social Sciences Citation Index (SSCI) and Science Citation Index Expanded (SCIE) databases of the Web of Science (WOS) service. The query string mainly follows 'digital innovation' related keywords, which we obtain from reading some highly-cited studies. The keywords include specific terms such as digital innovation, digital transformation, and digital disruption. During the prequery process, we find that some papers retrieved belong to unrelated fields, such as physics, mathematical, or biology. To exclude these unrelated published papers, we limit the search to include only those studies in specific search areas, including management and information science \& library science.

The search results in a total of 848 papers in the period from January 1, 2000 to June 13, 2020. We further collect the citation information for each of these papers from the WOS database. The citation information is used to construct the citation network which becomes the base for MPA.

\section{Analysis}

This section reveals the result of key-route MPA at 15 key-routes, which consists of 29 papers, and shown as Figure 1. In this figure, arrows indicate knowledge flow direction thus are pointing from the cited papers to the citing papers. Each paper is assigned a label that begins with the last name of the first author, continues with the first initials of the co-authors (in capital letters), and ends with the publishing year. The thickness of the links is proportional to their SPLC values.

\subsection{The development trajectory of digital innovation}

The role of digital technology has become more pronounced and advanced in various fields, playing an increasingly significant part in organizational innovation 
in the last two decades. Based on the analysis of the results of MPA, this study found that digital innovation is playing an even more vital role with the increased development of social and digital technologies. To specify the development of digital innovation literature, this study examined the literature on our main path, and divided the main research focus into three phases: radical technological change as digital disruption, the pursuit of digital innovation, and digital innovation management.

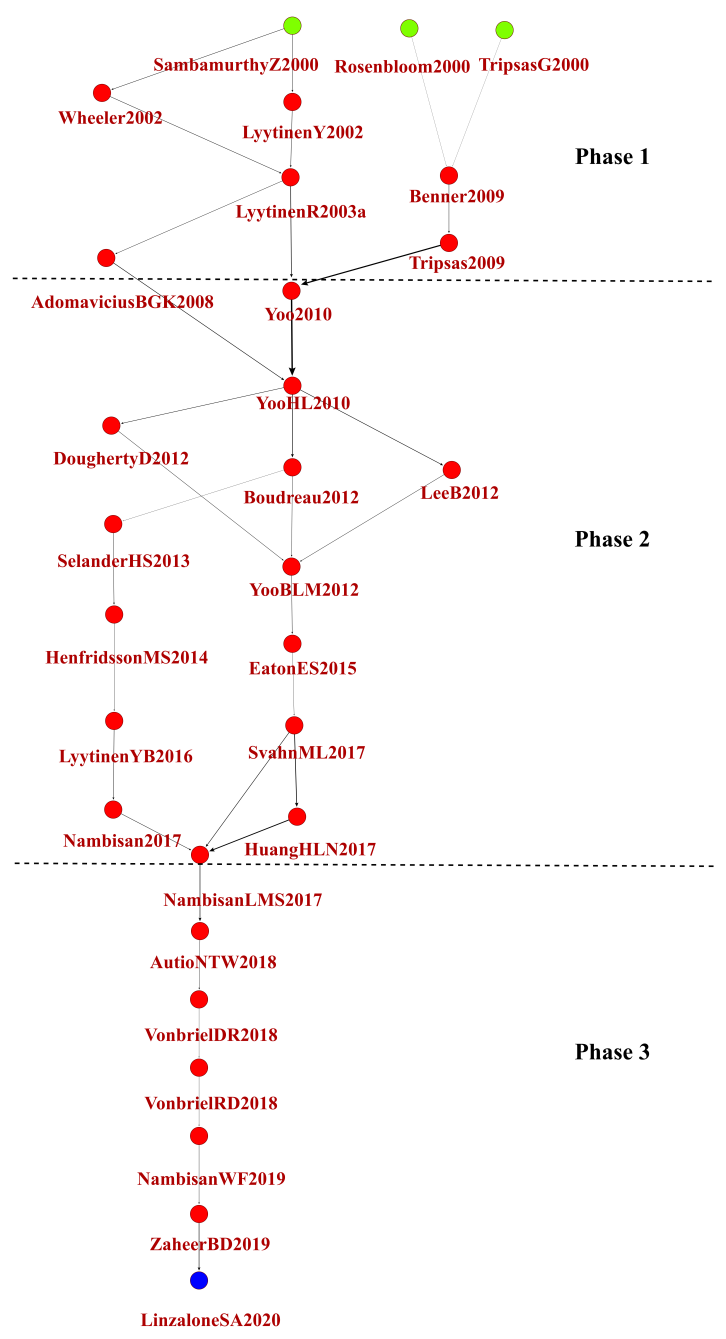

Figure 1. The development trajectory of digital innovation literature

3.1.1. Phase 1: Radical technological change as digital disruption By embedding digital technology into a traditional industry, the hybridization between

\begin{tabular}{|l|l|}
\hline Label & Reference \\
\hline \hline TripsasG2000 & {$[29]$} \\
\hline Rosenbloom2000 & {$[30]$} \\
\hline SambamurthyZ2000 & {$[26]$} \\
\hline LyytinenY2002 & {$[27]$} \\
\hline Wheeler2002 & {$[31]$} \\
\hline LyytinenR2003a & {$[32]$} \\
\hline AdomaviciusBGK2008 & {$[33]$} \\
\hline Tripsas2009 & {$[2]$} \\
\hline Benner2009 & {$[34]$} \\
\hline YooHL2010 & {$[1]$} \\
\hline Yoo2010 & {$[15]$} \\
\hline YooBLM2012 & {$[35]$} \\
\hline Boudreau2012 & {$[36]$} \\
\hline DoughertyD2012 & {$[37]$} \\
\hline LeeB2012 & {$[38]$} \\
\hline SelanderHS2013 & {$[39]$} \\
\hline HenfridssonMS2014 & {$[40]$} \\
\hline EatonES2015 & {$[41]$} \\
\hline LyytinenYB2016 & {$[42]$} \\
\hline Nambisan2017 & {$[43]$} \\
\hline SvahnML2017 & {$[44]$} \\
\hline HuangHLN2017 & {$[45]$} \\
\hline NambisanLMS2017 & {$[46]$} \\
\hline AutioNTW2018 & {$[47]$} \\
\hline VonbrielRD2018 & {$[48]$} \\
\hline VonbrielDR2018 & {$[49]$} \\
\hline NambisanWF2019 & {$[50]$} \\
\hline ZaheerBD2019 & {$[51]$} \\
\hline LinzaloneSA2020 & {$[52]$} \\
\hline
\end{tabular}

Table 1. The label of digital innovation literature

technologies and product-markets disrupts the established recipes of competition and business conduct [25]. As Figure 1 shows, there are three articles at the beginning of digital innovation studies. Firstly, TripsasG2000 recognized radical technological change as digital disruption and examines the company how to integrating capabilities and cognition helps to explain organizational inertia in the face of radical technological change [26]. Later, Lyytinen and Yoo [27] consider the rapid developments of information technology that stimulates various new types of computing based on users' nomadic behaviors, which benefit the IS community and play a significant role in reshaping the world. Moreover, Lyytinen and Rose [28] develop a model of disruptive IT innovation to further our understanding of qualitative changes in IT development processes and their outcomes.

Secondly, the researcher discusses digital disruption from a capability perspective. TripsasG2000 adopts 
the case of digital imaging to examine the role of managerial cognition in the dynamics of capabilities for radical technological discontinuities [29]. This perspective mainly focuses on the relationship between environment and managers, and thus deals with digital disruption by analyzing the hint of a new environment.Third, similar to the second article, Rosenbloom 2000 presents the real case of dealing with revolutionary technological change and indicates that no single theoretical perspective is sufficient to explain the path of innovative technology deployment [30]. In 2009, Benner2009 extends the dynamic capabilities view in facing a major technological change, which not only introduces an organizational routine perspective to the digital innovation literature but also further points out, an important point with regard to the effects of pervasive programs (process management activities) in management practice that affect capabilities and dynamic capabilities [30].

In this phase, an increasing amount of studies reveal the radical change feature of technological change. Some studies pay attention to how digital technologies disrupt the existing routines within an organization, and others focus on how to deal with digital disruption from a capability perspective. All of these perspectives shed light on the disruption of digital innovation.

3.1.2. Phase 2: The Pursuit of Digital innovation The digital innovation literature in the second phase discusses numerous approaches to fulfill digital innovation from various fields, which recognized digital innovation as an outcome for organizations to pursue. At the beginning of this period, Yoo2010 introduces the term - "digital innovation" to describe the phenomenon of integration of digital technologies and organizations, which emphasizes the digital elements of product innovation. It expands the intellectual boundaries of IS studies by presenting the implications of digitalization in the context of everyday experiences [15]. This study considers that the digital innovation study may focus on encompassing both behavioral and design sciences perspectives rather than any single perspective. Moreover, Yoo [15] recommends that the analysis of the changing meanings of time, actors, artifacts and place could be recognized as an approach to understanding the impact of radical digital convergence. It calls attention to reclaim the intellectual roots of the IS discipline as an artificial science by decisively broadening the scope of IS scholarship. Later, YooHL2010 develops a layered modular architecture to deepen the understanding of digital innovation, and thus to instigate profound changes in the ways that organizations manage digital innovation in the future [1].

By establishing four loosely coupled layers of devices, networks, services, and contents, there are increasing studies further discussing the digital strategy as well as the development of enterprise digital infrastructure to achieve digital innovation within an organization. Based on this architecture, there are mainly three research themes to discuss how to achieve digital innovation with an organization. First, Boudreau2012 analyses the specific institutional details of application development to explore the economic mechanisms of application innovation [36]. Second, Lee and Berente consider the digital product innovations lead to a transformative change in a variety of industries. They introduced digital control systems, integrated and coordinated both internally and externally designed components, to deal with the blurring boundaries of fairly modular product architectures [38]. Third, to achieve digital innovation, DoughertyD2012 suggested that innovators project forward with anticipation, therefore, reflecting both reframing and abduction to diminish the risks of complexity in complex domains. In contrast, the innovators may encounter inevitable resistances or miss the potential opportunity of recognizing discontinuous innovative patterns if they work locally [37].

Based on previous studies on digital innovation, there are two research themes in the latter of this phase. On the one hand, inspired by Yoo's modular layered architecture, some researchers still delve into the issues in further digital product innovation, such as how non-focal actors of the digital ecosystem address innovation problems [39]? and how to develop a more resilient approach to managing technological change. On the other hand, after Boudreau2012 indicated that in the role of heterogeneity and nonrandom entry and sorting in a digital platform, there is one research stream starting to translate attention to other areas. As Yoo et al. [35] mentioned, digital technologies are not merely present at the very core of the products, but also the services, and operations of many organizations. Moreover, EatonESY2015 presents how heterogeneous actors engage in the tuning of boundary resources within the digital platform [53].

In this phase, academics mainly recognized digital innovation as an outcome, from digital innovative product to service, business model, and even ecosystem. The researchers pay attention to the approach of digital technologies actualization in organizations.

3.1.3. Phase 3: Digital innovation management Compared to two former phases, the research direction 
in this phase is more directed, which mainly focuses on innovation management of digitalization. With digital technologies playing a more crucial role in an organization, the research focus of digital innovation management is becoming centralized. Due to the maturity of innovative technologies, there is a growing body of literature discussing the relationship between technology affordance and digital entrepreneurship. For example, AutioNTW2018 suggested that digital entrepreneurial ecosystems differ from traditional clusters by their emphasis on the exploitation of digital affordances [47]. Moreover, to minimize the risks of creating a new venture, vonBrielDR2018 investigated the influence of digital technology's conceptualization on digital entrepreneurship by analyzing the process of venture creation [48].

Moreover, we also found that the journals of the information system and organization field are dominant digitalization topics until entering into the third phase. In this phase, entrepreneurship-related journals play an increasingly important role in this digital economy phenomenon, which may give a hint about the importance of actualizing digital technology for business purposes. In the next section, this study will examine the potential research topics in this field.

\subsection{Sub themes}

To examine the main paths in more detail, this study further applies the global main path approach [54], which traces the top most significant paths thus revealing the recent and earlier clusters of papers. By increasing the number of paths selected, the details of the citation network surface little by little. Based on our analysis, seven branches of literature are clearly visualized in Figure 2. Each branch presents a sub research theme. Darker dots indicate end nodes. Link weights are indicated with different line thickness. Thicker lines note heavier weights. After examining the title, abstract, and keywords of these papers, these seven sub research themes are digital innovation management, the recombination approach, entrepreneurship, transformation, institution and management control, data-driven Value Capture. Moreover, we identify the major contribution from each research cluster by putting the code of the initial paper of each cluster below the label of the research themes.

3.2.1. Digital innovation management As figure 2 shows, digital innovation management is the most popular topic nowadays. In examining the studies in this research topic, we found that "digital innovation" is a term to present that people or organization who appropriate, design or develop a new thing (concept or artifact) into their place, which could be novel for them, but may not original, "new-to-the-world" objects. Because digital technology is intertwined with social systems and personal characteristics, people are able to create a relatively new product or service by their understanding of digital technologies and the environment. Therefore, the management approach of digital innovation arouses a number of researchers and practitioners' interests. Compared to existing digitalization, the topic of digital innovation management brings a novel concept, which emphasizes the sustainability of digitalization as an important factor in this field. NambisanLMS2017 is the most crucial article in this research theme, which not only presents the changing boundary of digital innovation in products, platforms, and even services, but also releases four new logics to theorize about the digitalization of innovation [46]. Nambisan, Lyytinen, Majchrzak, and Song's study calls attention to the temporal structure of innovation processes. More specifically, the digitization of innovation processes provide a new approach to breaking down the boundaries between different innovation phases and generates an increasing level of unpredictability and overlap in their time horizons [46]. This introductory research has a significant influence on the following articles, which brings four research themes that extend the scope of digital innovation management, such as the recombination approach, transformation, institution and management control, and data-driven value capture.

3.2.2. Recombination approach How to facilitate digitalization in organizations? As the previous subsection mentioned, digital innovation may not be a completely novel idea for enterprises. Specifically, appropriate, restructuring could be another approach to achieve digitalization. Considering the flexibility and malleability of digital technology, Henfridssona et al. suggested to rethink the digital resources in use from an open-ended value landscape, whose purpose through design recombination and use recombination to actualize the potential of multiple value paths [13]. Based on Henfridssona et al's value spaces framework, Holmström considered the framework provides a significant contribution in providing an approach to theorize from empirical observation by analyzing the role of digital resources in value creation and value capture [55]. 


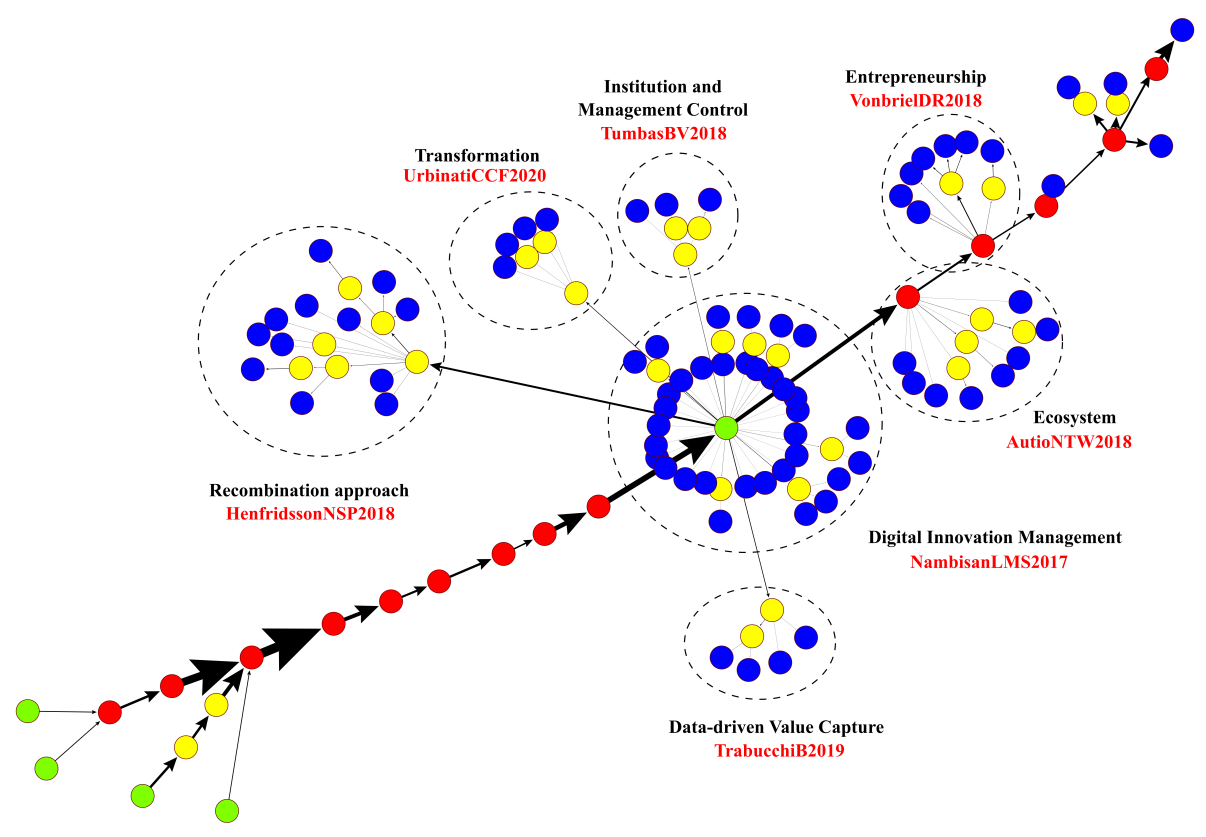

Figure 2. Multiple global main paths of digital innovation

3.2.3. Transformation Is digitalization a means, or an outcome? With the increasingly important role of digital technology in organizations, digitalization has become an approach for enterprises to conduct organizational change, which embeds digital technologies into an operational context to achieve transformation These digital artifacts represent a series of "new" factors for the member who is familiar with the existing process. Urbinati et al. adopt a change management perspective to identify the managerial actions of the organization and process that companies perform to deploy digital technologies in their open innovation processes [56]. Moreover, Magistretti et al. take advantage of artificial intelligence to create value, and thus foster the digital transformation of companies and society [57].

3.2.4. Institution and control management What is the change after the digital artifacts are deployed into organizations? The existing routine tasks may enact a series of "new" institutions to deal with the new context. As digital innovation becomes more ubiquitous in an organizational context, some studies start to pay attention to the institution and control management of digital innovation literature. According to Maguire et al's definition of institutional entrepreneurship [58], we considered that these digital innovation researchers through an institutional perspective institutionalizing digital innovation practices by connecting digitalization to stakeholders' routines and values.

The article of digital innovation and institutional entrepreneurship from Tumbas, Berente, and Brocke [59] is highly significant for the research theme of institution and control management. Due to the novel concept of digital innovation in the organization, the research indicates that Chief Digital Officer (CDO) gains legitimacy by intentionally emphasizing the term "digital" to distance themselves from existing executive roles. There are two critical functions during this process, one is developing the emerging digital logic of action, and the other is adopt a series of strategies to navigate tensions. Yet, the institution logic is not only enacted by the $\mathrm{CDO}$, but also from various professional practitioners, especially in when the institutional logics of an innovative technology challenge their professional practice [60].

3.2.5. Data-driven value capture Compared to the existing method of strategy formulation, data-based techniques is a novel approach to empower a series of value extraction initiatives. In this research theme of data-driven digital innovation, the researchers focus on how to extract the value from data, and thus to facilitate innovation and promote the efficiency of original processes. For example, Trabucchi and Buganza, through exploratory multiple case studies, explored the function of data in the innovation process [61]. Furthermore, the research indicated that analytics 
can be a key source of competitive advantage for organizations when their platforms collect an abundance of data [62].

3.2.6. Ecosystem The digital ecosystem is different from the traditional ecosystem, the feature of digital artifacts blurs the boundary between organizations. This new phenomenon is attracted the interests of both researchers and practitioners. Actualizing the accordance of digital technologies may provide organizations a new way to seize entrepreneurial opportunities, which also becomes an emerging phenomenon in the IS field and provides some research opportunities for academics to explore. According to Autio et al's perspective [47], entrepreneurial ecosystems could be recognized as "a digital economy phenomenon that harnesses technological affordances to facilitate entrepreneurial opportunity pursuit by new ventures through radical business model innovation."

3.2.7. Entrepreneurship Despite digital technology playing a significant role in entrepreneurial processes, Nambisan [63] pointed out that the role of digital technology has largely been neglected in existing entrepreneurship research. To further the understanding of the relationship between digital technology and entrepreneurship, von Briel et al. [49] reveal the enabler role of digital technologies during the venture creation processes. Integrating consideration of technologies and other factors into a process-oriented framework could benefit the analysis of how digital technologies enable new venture formation.

In studying the sub-themes of digital innovation, this study classifies these studies into three dimensions. Firstly, we examine the Digital Innovation Phenomenon, which includes Transformation, Ecosystem, and Entrepreneurship. This dimension mainly focuses on the outcome and consequence of digitalization. In other words, it indicates that enterprises, through digital technologies, conduct organizational renewal, develop emerging cooperative networks, and even shed light on potential opportunities for venture creation. Secondly, we look at the Digital Innovation Approach, comprising the Recombination Approach as well as Data-driven Value Capture. This research dimension aims to open the black box of digital innovation, which allows researchers to explore the key mechanisms behind digitalization. Thirdly, we discuss Digital Innovation Governance, including Digital Innovation Management as well as Institution and Management Control. The studies in this dimension treat digital innovation as a routine task and examine the managerial aspects of innovation activities.

\subsection{Digital Innovation road map}

This study acknowledges three research dimensions of digital innovation, yet, there still remain some fertile and under-researched areas for future study. Therefore, future studies can still explore some research dimensions in more detail. This study suggests three potential research directions for future research. These potential research themes are as follows: (1) The dark side of digital innovation (2) Balancing digital innovation and routine tasks (3) The dominant logic of Digital innovation.

3.3.1. The dark side of digital innovation While IS scholars have introduced the phenomenon of digital innovation enabling a bright society, the literature [64] points out the undesirable activities on the internet that may cause some social problems, such as cyber crimes and terror. Hence, this study argues that future research should consider exploring the side effects of digital innovation, and therefore transforming these problems into opportunities. As Lee (2016) [65] mentioned, organizations can reduce the dark side of digital technology by identifying the critical sources of risks and propose approaches.

\subsubsection{The dominant logic of digital innovation} Besides discussing the approach of digital innovation, this study suggests exploring the dominant logic of this field. The dominant logic has not only been recognized as a crucial issue in organizational change [66], but also a fundamental approach to innovating [67]. However, the dominant logic of digital innovation is still an unexplored research area. Thus, we make a call for future research for studies to explore the dominant logic of digital innovation to facilitate innovative initiatives.

\subsubsection{Balancing digital innovation and routine} tasks Existing studies mainly treat the governance of digital innovation as an enabler of organizational renewal. Yet, few studies focus on the dilemma of digital innovation within organizations. More specifically, how to balance digital innovation and routine tasks has become a major challenge within organizations regarding the transformation process. Accordingly, this study calls for future studies to develop the balancing mechanisms between digital innovation and routine activities. 
As this section examines, there are many open research issues related to digital innovation. We believe that so far we have seen only a fraction of digital innovation. Future research within this field should explore the above potential research themes to create a better understanding of digital innovation.

\section{Discussion \& Conclusion}

The past two decades have witnessed a clear growth of research interest in digital innovation. Despite this topic having been discussed since 2000, digital technologies nowadays have presented a significant change in comparison to the original one. Based on the main path analysis, we gain a key research path with 29 articles by analyzing 848 papers in the digital innovation literature. It allows this study to trace the development trajectory of digital innovation, and explore the changing role of digital innovation in organizations.

In response to the first question, we through main path analysis explored the research on digital innovation literature in three phases. First, radical technological change as digital disruption. By introducing digital technologies into the traditional industry, the digital-based product disrupts the established recipes of competition and business conduct. The research in this phase mainly focuses on how to deal with the challenge of radical technical change. Second, pursuing digital innovation. Digital technology becomes more common in this phase, and digitalization becomes an objective of organization. Also, It attracts academics to pay attention to the type of digital innovation. The digital innovation literature in this phase mainly focus on the product level. The research agenda from Yoo, Henfridsson, and Lyytinen plays a crucial role in this phase, which through an architecture of four loosely coupled layers deepen the study in product digitalization [1]. Third, digital innovation management. Digital innovation not merely includes products, but also services, business models, ecosystems, and so on. It becomes an innovative means for organizations to fulfill organizational needs. Due to the maturity of innovative technologies, a growing literature discussing various management approach of digitalization.

To clarify the new objects in digital innovation, this study through the global main path approach [54], a citation-based literature survey, traces the top most significant paths thus revealing the popular research themes. Based on the analysis result, we gain seven research themes, namely digital innovation management, recombination approach, entrepreneurship, transformation, institution and management control, and data-driven value capture. The research theme of digital innovation management is the most popular topic in this field, which makes the management approach of digitalization begin to flourish. Going deeper with the innovation management literature, academics reveals a series of topics. The recombination approach, purposed by Henfridssona et al.[13], is another prevalent theme in these clusters, which allows researchers to rethink both design recombination and use recombination and to actualized the digitalization for value creation. Moreover, institutionalization is another approach to manage digitalization. Tumbas, Berente, and Brocke recommended that institutionalizing digital innovation practices by connecting digitalization to stakeholders' routines and values could be another way of innovation management [59].

Moreover, this study classifies the seven research themes into three research dimensions, including the dark side of digital innovation, the dominant logic of digital innovation and balancing digital innovation and routine tasks. To help guide future studies of digital innovation, this study follows the existing dimensions of this filed, and suggest three potential research directions for further research: The dark side of digital innovation, Balancing digital innovation and routine tasks, and The dominant logic of digital innovation. These also provide fruitful opportunities for further research.

In conclusion, this study extends prior research on digital innovation by painting an overall picture of the research on the digital innovation field from a perspective different from previous studies. For researchers, this paper contributes to the conceptual foundation of digital innovation by integrating the different dimensions. For practitioners, we suggest that managers rethink the meaning and value of digital innovation before they embrace emerging digital technology, rather than pursuing innovative technology for short-lived benefits. Based on our analysis, this study could further the understanding of digital innovation in the current IS research and reveal research opportunities that are helpful for future work.

\section{References}

[1] Y. Yoo, O. Henfridsson, and K. Lyytinen, "Research commentary - the new organizing logic of digital innovation: an agenda for information systems research.," Information systems research, pp. 21(4), 724-735, 2010.

[2] M. Tripsas, "Technology, identity, and inertia through, the lens of "the digital photography company.," Organization science, pp. 20(2), 441-460, 2009.

[3] A. L. Hadida and T. Paris, "Managerial cognition and the 
value chain in the digital music industry.," Technological Forecasting and Social Change, pp. 83, 84-97, 2014.

[4] J. Karimi and Z. Walter, "The role of dynamic capabilities in responding to digital disruption: A factor-based study of the newspaper industry.," Journal of Management Information Systems, pp. 32(1), 39-81, 2015.

[5] R. Kohli and N. P. Melville, "Digital innovation: A review and synthesis.," Information Systems Journal, pp. 29(1), 200-223, 2019.

[6] R. Agarwal, G. Gao, C. DesRoches, and A. K. Jha, "Research commentary - the digital transformation of healthcare: Current status and the road ahead.," Information Systems Research, pp. 21(4), 796-809, 2010.

[7] T. Hess, C. Matt, A. Benlian, and F. Wiesböck, "Options for formulating a digital transformation strategy.," MIS Quarterly Executive, p. 15(2), 2016.

[8] A. Utesheva, J. R. Simpson, and D. Cecez-Kecmanovic, "Identity metamorphoses in digital disruption: a relational theory of identity.," European Journal of Information Systems, pp. 25(4), 344-363, 2016.

[9] J. Bughin, "The best response to digital disruption.," Information Systems Research, p. 58(4), 2017.

[10] M. Barrett, E. Davidson, J. Prabhu, and S. L. Vargo, "Service innovation in the digital age: key contributions and future directions.," MIS quarterly, pp. 39(1), 135-154, 2015.

[11] C. Zott and R. Amit, "Business model innovation: How to create value in a digital world.," Marketing Intelligence Review, pp. 9(1), 18-23, 2017.

[12] A. Ghezzi and A. Cavallo, "Agile business model innovation in digital entrepreneurship: Lean startup approaches.," Journal of business research, pp. 110, 519-537, 2020.

[13] O. Henfridsson, J. Nandhakumar, H. Scarbrough, and N. Panourgias, "Recombination in the open-ended value landscape of digital innovation. information and organization," MIS quarterly, pp. 28(2), 89-100, 2018.

[14] B. Hinings, T. Gegenhuber, and R. Greenwood, "Digital innovation and transformation: An institutional perspective.," Information and Organization, pp. 28(1), 52-61, 2018.

[15] Y. Yoo, "Computing in everyday life: A call for research on experiential computing.," MIS quarterly, pp. 213-231, 2010.

[16] N. P. Hummon and P. Dereian, "Connectivity in a citation network: The development of dna theory.," Social networks, pp. 11(1), 39-63, 1989.

[17] Y. Xiao, L. Y. Lu, J. S. Liu, and Z. Zhou, "Knowledge diffusion path analysis of data quality literature: A main path analysis.," Journal of Informetrics, pp. 8(3), 594-605., 2014.

[18] H. Liang, J. J. Wang, Y. Xue, and X. Cui, "It outsourcing research from 1992 to 2013: A literature review based on main path analysis.," Information \& Management, pp. 53(2), 227-251., 2016.

[19] H. Park and C. L. Magee, "Tracing technological development trajectories: A genetic knowledge persistence-based main path approach.," PloS one, p. 12(1)., 2017.
[20] S. Bhupatiraju, O. Nomaler, G. Triulzi, and B. Verspagen, "Knowledge fows: Analyzing the core literature of innovation, entrepreneurship and science and technology studies.," Research Policy, pp. 41(7), 1205-1218, 2012.

[21] J. S. Liu, L. Y. Lu, and M. H. C. Ho, "A few notes on main path analysis.," Scientometrics, pp. 119(1), 379-391, 2019.

[22] J. S. Liu, L. Y. Lu, and M. H. C. Ho, "A note on choosing traversal counts in main path analysis.," Scientometrics, pp. 1-3, 2020.

[23] J. S. Liu and L. Y. Lu, "An integrated approach for main path analysis: development of the hirsch index as an example.," Journal of the American Society for Information Science and Technology, pp. 63 (3), 528-542., 2012.

[24] S. C. Hung, J. S. Liu, L. Y. Lu, and Y. C. Tseng, "Technological change in lithium iron phosphate battery: the key-route main path analysis.," Scientometrics, pp. 100(1), 97-120, 2014.

[25] C. M. Christensen, The Innovator's Dilemma: When New Tech nologies Cause Great Firms to Fail. Harvard Business School Press, Cambridge, MA., 1997.

[26] V. Sambamurthy and R. W. Zmud, "Research commentary: The organizing logic for an enterprise's it activities in the digital era- a prognosis of practice and a call for research.", Information systems research, pp. 11(2), 105-114., 2000.

[27] K. Lyytinen and Y. Yoo, "Research commentary: the next wave of nomadic computing.," Information systems research, pp. 13(4), 377-388, 2000.

[28] K. Lyytinen and G. M. Rose, "The disruptive nature of information technology innovations: the case of internet computing in systems development organizations.," $M I S$ quarterly, pp. 557-596, 2003.

[29] M. Tripsas and G. Gavetti, "Capabilities, cognition, and inertia: Evidence from digital imaging.," Strategic management journal, pp. 21(10-11), 1147-1161, 2000.

[30] R. S. Rosenbloom, "Leadership, capabilities, and technological change: The transformation of ncr in the electronic era.," Strategic Management Journal, pp. 1083-1103, 2000.

[31] B. C. Wheeler, "Nebic: A dynamic capabilities theory for assessing net-enablement.," Information systems research, pp. 13(2), 125-146., 2002.

[32] K. Lyytinen and G. M. Rose, "The disruptive nature of information technology innovations: the case of internet computing in systems development organizations.," MIS quarterly, pp. 557-596., 2018.

[33] G. CAdomavicius, J. C. Bockstedt, A. Gupta, and R. J. Kauffman, Making sense of technology trends in the information technology landscape: A design science approach. Publisher, 2008.

[34] M. J. Benner, "Dynamic or static capabilities? process management practices and response to technological change.," Journal of product innovation management, pp. 26(5), 473-486., 2009.

[35] Y. Yoo, R. J. Boland Jr, K. Lyytinen, and A. Majchrzak, "Organizing for innovation in the digitized world.," Organization science, pp. 23(5), 1398-1408., 2012.

[36] K. J. Boudreau, "Let a thousand flowers bloom? an early look at large numbers of software app developers and patterns of innovation.," Organization Science, pp. 23(5), 1409-1427., 2012. 
[37] D. Dougherty and D. D. Dunne, "Digital science and knowledge boundaries in complex innovation. organization science.," Organization Science, pp. 23(5), 1467-1484., 2012.

[38] J. Lee and N. Berente, "Digital innovation and the division of innovative labor: Digital controls in the automotive industry.," Organization Science, pp. 23(5), 1428-1447., 2012.

[39] L. Selander, O. Henfridsson, and F. Svahn, "Capability search and redeem across digital ecosystems," Journal of information technology, pp. 28(3), 183-197., 2013.

[40] O. Henfridsson, L. Mathiassen, and F. Svahn, "Managing technological change in the digital age: the role of architectural frames.," Journal of information technology, pp. 29(1), 27-43., 2014.

[41] B. Eaton, S. Elaluf-Calderwood, C. Sorensen, and Y. Yoo, "Distributed tuning of boundary resources: the case of apple's ios service system.," MIS Quarterly, pp. 39(1), 217-243., 2015.

[42] K. Lyytinen, Y. Yoo, and R. J. Boland Jr, "Digital product innovation within four classes of innovation networks.," Information Systems Journal, pp. 26(1), 47-75., 2016.

[43] S. Nambisan, "Digital entrepreneurship: Toward a digital technology perspective of entrepreneurship.," Entrepreneurship Theory and Practice, pp. 41(6), 1029-1055., 2017.

[44] F. Svahn, L. Mathiassen, and R. Lindgren, "Digital innovation in incumbent firms: How volvo cars managed competing concerns.," Mis Quarterly, p. 41(1), 2017.

[45] J. Huang, O. Henfridsson, M. J. Liu, and S. Newell, "Growing on steroids: Rapidly scaling the user base of digital ventures through digital innovaton.," Mis Quarterly, p. 41(1), 2016.

[46] S. Nambisan, K. Lyytinen, A. Majchrzak, and M. Song, "Digital innovation management: Reinventing innovation management research in a digital world.," Mis Quarterly, p. 41(1), 2017.

[47] F. von Briel, P. Davidsson, and J. Recker, "Digital affordances, spatial affordances, and the genesis of entrepreneurial ecosystems.," Strategic Entrepreneurship Journal, pp. 12(1), 72-95., 2018.

[48] F. von Briel, J. Recker, and P. Davidsson, "Not all digital venture ideas are created equal: Implications for venture creation processes," The Journal of Strategic Information Systems, pp. 27(4), 278-295., 2018.

[49] F. von Briel, P. Davidsson, and J. Recker, "Digital technologies as external enablers of new venture creation in the it hardware sector.," Entrepreneurship Theory and Practice, pp. 42(1), 47-69., 2018.

[50] S. Nambisan, M. Wright, and M. Feldman, "The digital transformation of innovation and entrepreneurship: Progress, challenges and key themes.," Research Policy, pp. 48(8), 103773., 2019.

[51] H. Zaheer, Y. Breyer, and J. Dumay, "Digital entrepreneurship: An interdisciplinary structured literature review and research agenda.," Technological Forecasting and Social Change, pp. 148, 119735., 2016.

[52] R. Linzalone, G. Schiuma, and S. Ammirato, "Connecting universities with entrepreneurship through digital learning platform: functional requirements and education-based knowledge exchange activities.," International Journal of Entrepreneurial Behavior \& Research, 2020.
[53] B. Eaton, S. Elaluf-Calderwood, C. Sorensen, and Y. Yoo, "Distributed tuning of boundary resources: the case of apple's ios service system.," MIS Quarterly: Management Information Systems, pp. 39(1), 217-243., 2015.

[54] J. S. Liu, L. Y. Lu, W. M. Lu, and B. J. Lin, "Data envelopment analysis 1978-2010: A citation-based literature survey.," Omega, pp. 41(1), 3-15., 2020.

[55] J. Holmström, "Recombination in digital innovation: Challenges, opportunities, and the importance of a theoretical framework.," Information and Organization, pp. 28(2), 107-110., 2018.

[56] A. Urbinati, D. Chiaroni, V. Chiesa, and F. Frattini, "The role of digital technologies in open innovation processes: an exploratory multiple case study analysis.," $R \& D$ Management, pp. 50(1), 136-160., 2020.

[57] S. Magistretti, C. Dell'Era, and A. M. Petruzzelli, "How intelligent is watson? enabling digital transformation through artificial intelligence.," Business Horizons, pp. 62(6), 819-829., 2019.

[58] S. Magistretti, C. Dell'Era, and A. M. Petruzzelli, "Institutional entrepreneurship in emerging fields: Hiv/aids treatment advocacy in canada.," Academy of management journal, pp. 47(5), 657-679., 2004.

[59] S. Tumbas, N. Berente, and J. V. Brocke, "Digital innovation and institutional entrepreneurship: Chief digital officer perspectives of their emerging role.," Journal of Information Technology, pp. 33(3), 188-202., 2018.

[60] R. Bernardi and M. Exworthy, "Clinical managers' identity at the crossroad of multiple institutional logics in it innovation: The case study of a health care organization in england.," Information Systems Journal, pp. 30(3), 566-595., 2020.

[61] D. Trabucchi and T. Buganza, "Data-driven innovation: switching the perspective on big data.," European Journal of Innovation Management., 2019.

[62] M. Jocevski, A. Ghezzi, and N. Arvidsson, "Exploring the growth challenge of mobile payment platforms: A business model perspective.," Electronic Commerce Research and Applications, pp. 40, 100908., 2020.

[63] S. Nambisan, "Digital entrepreneurship: Toward a digital technology perspective of entrepreneurship.," Entrepreneurship Theory and Practice, pp. 41(6), 1029-1055, 2016

[64] J. K. Lee, "Data-driven innovation: switching the perspective on big data.," MIS quarterly, pp. 39(2), iii-xii, 2015.

[65] J. K. Lee, "Invited commentary-reflections on ict-enabled bright society research.," Information Systems Research, pp. 27(1), 1-5, 2016.

[66] T. C. Chou, S. H. Wu, J. R. Chen, and C. H. Huang, "Exploring dominant business logic transformation practices: a routine enactment perspective.," Technology Analysis \& Strategic Management, pp. 32(10), 1142-1155., 2020.

[67] R. F. Lusch and S. Nambisan, "Service innovation: A service-dominant logic perspective.," MIS quarterly, pp. 39(1), 155-176., 2015. 